Goldschmidt 2021 Abstract

https://doi.org/10.7185/gold2021.7279

\section{Towards a better understanding of mercury (Hg) dynamics in the marine environment}

\author{
SONJA GINDORF ${ }^{1}$, ALINA KLEINDIENST ${ }^{2}$, LUISA M \\ MALBERTI $^{3}$, ISABEL GARCÍA GARCÍA ARÉVALO ${ }^{4}$, \\ NATALIA TORRES-RODRIGUEZ ${ }^{5}$, DAVID AMPTMEIJER ${ }^{6}$, \\ DAVID AMOUROUX ${ }^{7}$, DAVID POINT ${ }^{3}$, JOËL KNOERY ${ }^{8}$, \\ REMY GUYONEAUD ${ }^{9}$, ANNE LORRAIN ${ }^{10}$, JOHANNES \\ BIESER $^{11}$, MILENA HORVAT ${ }^{12}$, CORINNA SCHRUM ${ }^{6}$, \\ EMMANUEL TESSIER $^{13}$, JEROEN E SONKE ${ }^{14}$, SOFI \\ JONSSON $^{1}$ AND LARS-ERIC HEIMBUERGER-BOAVIDA ${ }^{15}$ \\ ${ }^{1}$ Stockholm University \\ ${ }^{2}$ Université de Pau et des Pays de l'Adour, E2S UPPA, CNRS, \\ IPREM, Institut des Sciences Analytiques et de Physico-chimie \\ pour l'Environnement et les matériaux \\ ${ }^{3}$ Géosciences Environnement Toulouse, CNRS/IRD/Université \\ Paul Sabatier Toulouse III \\ ${ }^{4}$ IFREMER Centre Atlantique \\ ${ }^{5}$ Institut Méditerranéen d'Océanologie \\ ${ }^{6}$ Helmholtz-Zentrum Geesthacht Centre for Materials and \\ Coastal Research \\ ${ }^{7}$ CNRS, Université de Pau et Pays de l'Adour, E2S UPPA, \\ IPREM \\ ${ }^{8}$ IFREMER \\ ${ }^{9}$ Pau University \\ ${ }^{10}$ IRD \\ ${ }^{11}$ Helmholtz-Zentrum Hereon \\ ${ }^{12}$ Jožef Stefan Institute \\ ${ }^{13}$ Université de Pau et des Pays de l'Adour, E2S UPPA, CNRS, \\ IPREM \\ ${ }^{14} \mathrm{CNRS} /$ Université de Toulouse \\ ${ }^{15}$ Institut Méditerranéen d'Océanologie - MIO, CNRS \\ Presenting Author: sonja.gindorf@aces.su.se
}

Mercury $(\mathrm{Hg})$ is a highly toxic pollutant of global relevance, whereby monomethyl mercury (MMHg) is of special concern for human health due to its neurotoxicity and biomagnification in aquatic food webs. Although $\mathrm{Hg}$ in oceans has been studied for decades, large knowledge gaps remain concerning $\mathrm{Hg}$ transformations and fluxes. The GMOS-Train network has been created to investigate $\mathrm{Hg}$ transformations and the biogeochemical $\mathrm{Hg}$ cycle. Combining aquatic biogeochemistry, ecology and analytical chemistry we aim to provide the basis for improved multimedia modelling. Moreover, we strive to provide scientific results for policymaking, thereby contributing to the assessment of the implementation of the Minamata Convention.

Herein, we present one work package of GMOS-Train which is fully dedicated to investigating marine $\mathrm{Hg}$ dynamics in coastal and open ocean marine environments. On a global basis, the ocean functions as a large $\mathrm{Hg}$ reservoir and as a temporary sink to anthropogenic $\mathrm{Hg}$ emissions. For the population, consumption of seafood is the main exposure pathway of $\mathrm{Hg}$ [1]. Advances in clean sampling protocols and analytical methods enabled the observation of $\mathrm{Hg}$ species distribution in the Arctic, Atlantic
Pacific and Southern Ocean [2]. Due to the absence of traceable and validated methodologies for the determination of low concentrations of different mercury species in the marine environment, metrological comparability of the measurement results still needs to be demonstrated, which is also one of the objectives of GMOS-Train. Further, the program aims to investigate $\mathrm{Hg}$ and $\mathrm{MMHg}$ (bio)-transformations, and bioaccumulation in lower food webs in marine environments, sorption and uptake rates by key marine particles and the role of natural organic matter (NOM) in $\mathrm{Hg}$ reactivity.

We will present general approaches and experimental set-ups, used to achieve the stated goals such as (i) enriched stable isotope techniques, (ii) differences in analytical approaches for $\mathrm{Hg}$ speciation at ultra-trace level ( $\mathrm{Hg}(\mathrm{II}), \mathrm{Hg}(0), \mathrm{MMHg}$, $\mathrm{DMHg}$,(iii) application of stable isotope ratios, and (iv) results of the first inter-comparison and training event.

[1] Outridge et al. (2018), ES\&T. 52, 11466-11477.

[2] Bowman et al. (2020), Sci. Total Environ. 710, 136166. 